\title{
Calcium-Dependent Translocation of S100B Is Facilitated by Neurocalcin Delta
}

\author{
Jingyi Zhang ${ }^{1}$, Anuradha Krishnan ${ }^{1}$, Hao $\mathrm{Wu}^{1}$ and Venkat Venkataraman ${ }^{1,2, *}$ \\ 1 Department of Cell Biology and Neuroscience, Graduate School of Biomedical Sciences, \\ School of Osteopathic Medicine, Rowan University, Stratford, NJ 08084, USA; serenazjy@gmail.com (J.Z.); \\ krishnan@rowan.edu (A.K.); haowubiomed@gmail.com (H.W.) \\ 2 Department of Rehabilitation Medicine, NeuroMusculoskeletal Institute, School of Osteopathic Medicine, \\ Rowan University, Stratford, NJ 08084, USA \\ * Correspondence: venkatar@rowan.edu; Tel.: +1-856-566-6418
}

Citation: Zhang, J.; Krishnan, A.; Wu, H.; Venkataraman, V. CalciumDependent Translocation of S100B Is Facilitated by Neurocalcin Delta. Molecules 2021, 26, 227. https://doi.org/10.3390/ molecules 26010227

Academic Editor: Derek J. McPhee Received: 14 December 2020 Accepted: 28 December 2020 Published: 5 January 2021

Publisher's Note: MDPI stays neutral with regard to jurisdictional clai$\mathrm{ms}$ in published maps and institutional affiliations.

Copyright: (C) 2021 by the authors. Licensee MDPI, Basel, Switzerland. This article is an open access article distributed under the terms and conditions of the Creative Commons Attribution (CC BY) license (https:// creativecommons.org/licenses/by/ $4.0 /)$.

\begin{abstract}
S100B is a calcium-binding protein that governs calcium-mediated responses in a variety of cells-especially neuronal and glial cells. It is also extensively investigated as a potential biomarker for several disease conditions, especially neurodegenerative ones. In order to establish S100B as a viable pharmaceutical target, it is critical to understand its mechanistic role in signaling pathways and its interacting partners. In this report, we provide evidence to support a calcium-regulated interaction between S100B and the neuronal calcium sensor protein, neurocalcin delta both in vitro and in living cells. Membrane overlay assays were used to test the interaction between purified proteins in vitro and bimolecular fluorescence complementation assays, for interactions in living cells. Added calcium is essential for interaction in vitro; however, in living cells, calcium elevation causes translocation of the NCALD-S100B complex to the membrane-rich, perinuclear trans-Golgi network in COS7 cells, suggesting that the response is independent of specialized structures/molecules found in neuronal/glial cells. Similar results are also observed with hippocalcin, a closely related paralog; however, the interaction appears less robust in vitro. The N-terminal region of NCALD and HPCA appear to be critical for interaction with S100B based on in vitro experiments. The possible physiological significance of this interaction is discussed.
\end{abstract}

Keywords: S100B; neurocalcin delta; hippocalcin; calcium; translocation

\section{Introduction}

Calcium is a versatile second messenger that plays a pivotal role in a variety of physiological processes. Changes in intracellular calcium concentration can trigger multiple, diverse signaling pathways and processes ranging from fertilization to muscle contraction under normal conditions and neurodegenerative diseases and cancer in pathological states. The tight spatial and temporal regulation of responses to changes in intracellular calcium, arguably, is of the greatest significance in modulating neuronal activity. Such modulation occurs directly within neurons and indirectly through astrocyte/glial pathways.

Ever since the identification of neuroglia by Rudolph Virchow [1] and astrocyte independently by Michael von Lenhosseck, Kolliker and Anderiezen (reviewed in: [2]), as part of the brain, their role has been shifting towards more active participation in neuronal activity rather than passive support. While the effect of calcium signaling within the neurons on modulating neuronal activity has been well-established and accepted, the role for the astrocyte/glial signaling has gone through waves of acceptance and questioning [3]. It is suggested that two aspects may account for observed discrepancies: the hormetic response (opposing effects based on concentration; reviewed in [4-6]) elicited by calcium and subcellular compartmentalization.

S100B, primarily astrocytic in origin, is a unique signaling molecule that impacts multiple signaling pathways in a hormetic fashion-sometimes negatively, sometimes 
positively $[7,8]$. The $\mathrm{S} 100$ family now includes more than 20 genes paralogous to S100B, with functions in healthy and diseased states [9]; however, the focus for this report is S100B. S100B is a homodimer of a 92-amino acid protein, termed S100b, with a molecular mass of 10,713 Da, but migrates between 9 and $14 \mathrm{kDa}$ on SDS-polyacrylamide gels. Crystal structures and refined NMR structures $[10,11]$ reveal that the monomer contains two EFhands-one non-canonical and one conventional-that bind calcium. S100B can bind calcium and undergo a conformational change, which allows it to control cellular activity by interacting with other proteins-a feature of most S100 proteins (reviewed in [12]). However, these conformational changes are unlike other more conventional EF-containing proteins and are unique for S100B protein [13]. The neuronal calcium sensor (NCS) proteins, for example, have a relatively hydrophobic $\mathrm{N}$-terminal region (often myristoylated) that is buried in the calcium-free state and is exposed upon binding of calcium. This exposed region then interacts with target proteins-sometimes additional regions are also involved. In contrast to this largely hydrophobic interacting surface in NCS proteins, S100B surface is abundantly populated with charged residues-both negative and positive; in addition, the hydrophobic interfacial cleft is also exposed upon calcium binding. Thus, a broader and flatter surface for interaction — ionic and hydrophobic — explains the ability to bind to a variety of proteins, further confounding the ability to predict interacting surfaces based on protein sequence alone $[12,14,15]$. The difference between the conformational changes in NCS proteins and S100B has also been demonstrated experimentally through calcium-induced mobility shift assays [13]: binding to calcium results in a mobility shift in the NCS proteins, but no such shift is observed with S100B. Even among the S100 family, S100B appears to be uniquely designed for interactions. Thus, the S100B protein is uniquely specialized to sense changes in calcium levels and mediates appropriate responses, especially in the nervous system.

Expression of S100B in the nervous system is primarily in the glial cells-astrocytes in the central nervous system and Schwann cells in the peripheral nervous system, where they carry out intracellular and extracellular functions (reviewed in $[7,8,16])$. S100B functions as a modulator of protein phosphorylation, enzyme activation and calcium homeostasis intracellularly; it also alters transcription impacting cell proliferation and migration, apoptosis and differentiation extracellularly. These functions are mediated primarily through RAGE (Receptor for Advanced Glycation Endproducts) and Toll-Like Receptors (TLRs) known to date. At the organism level, S100B contributes to a range of processes from neurodegeneration to cardiomyocyte remodeling, from melanomas to gliomas. Since these functions are relevant to both healthy and diseased states and, since S100B is detectable in human serum and cerebrospinal fluid (CSF), a focused effort has been under way to determine if S100B could serve as a biomarker for various diseases (reviewed in: [17-23]) and a therapeutic target (reviewed in: $[17,24-28]$ ). However, understanding the mechanism of action is critical in determining the validity of a pharmaceutical target for therapy.

The dual nature of action - intra- and extracellular-by S100B (reviewed in: [7,16,29]) poses a significant challenge in delineating its precise mechanism of action in many instances. Further challenges are imposed by the compartmentalization of S100B expression and its interacting partners. For example, in the retina, it has been demonstrated that $\mathrm{S} 100 \mathrm{~B}$ is expressed and stimulates the rod outer segment membrane guanylate cyclase (ROS-GC); however, differences in the biochemical properties of the protein [30-32] and the histochemical localization within the retina have been observed [31,33,34]. In order to develop effective strategies of using S100B as a therapeutic/pharmacological target, it is essential to examine its subcellular localization and interacting partners-especially in the context of changing intracellular calcium concentrations. In this report, interaction of S100B with another neuronal calcium sensor protein, neurocalcin delta (NCALD) has been characterized both in vitro as well asin living cells in culture, and the response to changing intracellular calcium levels has been documented. In addition, possible binding of S100B to hippocalcin (HPCA) — a close homolog of NCALD—has also been similarly analyzed. 


\section{Results}

\subsection{NCALD and S100B Interact In Vitro}

It has been suggested that S100B is one of the target proteins of NCALD and that the S100B-NCALD complex may be involved in $\mathrm{Ca}^{2+}$ signaling in the glial cell [35]. Therefore, it was of interest to determine if NCALD and S100B bind and if they did, whether the binding contributed to the cellular response to calcium signals. As a first step, purified S100B and NCALD were used for in vitro binding assays through membrane overlay. Hippocalcin (HPCA) is another neuronal calcium sensor protein within the VILIP family, which shares $88 \%$ identity (95\% similarity) at the primary amino acid sequence level with NCALD [36]. Therefore, HPCA was also used to test binding as described in "Materials and Methods". An additional protein that does not bind calcium, ovalbumin, was used as a control. The results are presented in Figure 1.

$\boldsymbol{A}$

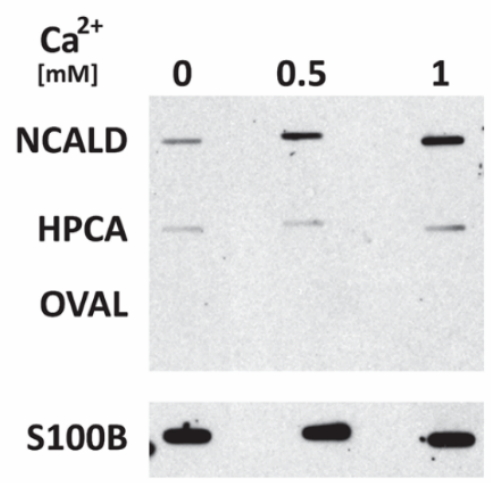

B

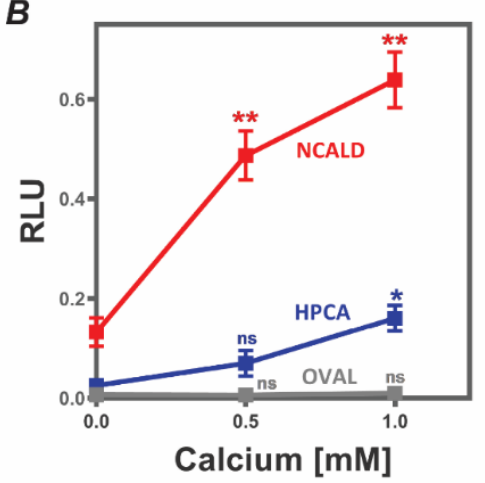

Figure 1. NCALD binds to S100B in vitro: Purified neurocalcin delta (NCALD), hippocalcin (HPCA) and commercial ovalbumin (OVAL) were blotted onto nitrocellulose and the membrane was then incubated with $\mathrm{S} 100 \mathrm{~B}$ in the presence of indicated concentrations of $\mathrm{CaCl}_{2}$. After $1 \mathrm{~h}$ incubation, the blot was washed with buffer. Bound S100B was detected using its antibody following standard Western blotting protocol and ECL detection. (A) A representative blot. (B) Data provided was collected from at least five independent experiments with three different preparations of the proteins. Intensity for each band was measured over the background using imageJ and then plotted (mean \pm SEM) as relative luminescence unit (RLU) in Prism (9.0). Student's $t$-test was carried out for each protein to determine significance compared to values obtained at $0 \mathrm{mM}$ calcium. ns $p>0.01$; ${ }^{*} p \leq 0.05 ;{ }^{* *} p \leq 0.01$.

The results suggest that S100B binds to both NCALD and HPCA, but better to NCALD than HPCA. There is no binding to ovalbumin. Furthermore, the binding of S100B to NCALD and HPCA is facilitated by calcium.

\subsection{Binding to S100B Requires the N-Terminal Region of NCALD that Houses EF1 Hand}

NCALD and HPCA share $88 \%$ amino acid identity and 95\% similarity yet exhibited differential binding to S100B. To further investigate the binding site, we created chimeric proteins: NCHC, which contains the N-terminal region of NCALD encompassing the EF1 hand, but the remaining three EF hands of HPCA; HCNC, which contains the corresponding region from HPCA, but the remaining three EF hands of NCALD (Figure 2A). Purified NCHC and HCNC were tested in membrane overlay. The results showed (Figure 2B) that NCHC binding to S100B is similar to NCALD, while HCNC binding is comparable to that of HPCA. The observation suggests that the N-terminal region including the EF hand 1-the most divergent region between NCALD and HPCA — constitutes the binding site for S100B in both the proteins. It is noted that the calcium-dependence of binding is less robust in NCHC when compared to NCALD. A similar result, albeit less striking, is also observable with HCNC when compared to HPCA. It remains to be explored whether this is due to the altered binding or altered calcium-sensing in the chimeric proteins. 
A

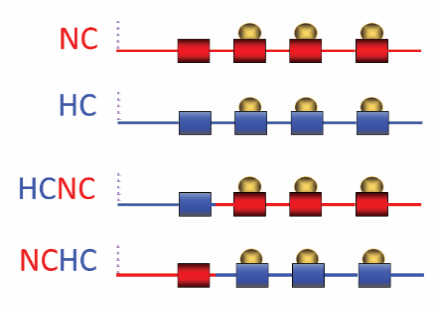

$B$

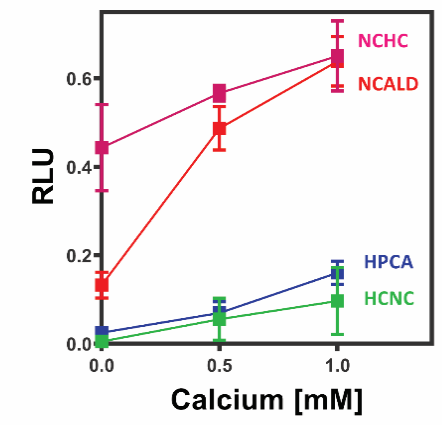

Figure 2. The N-terminal region of NCALD is necessary for the binding to S100B in vitro: (A) Chimeric constructs of NCALD and HPCA were created where the N-terminal region including the EF1 hand was swapped between the two proteins. EF hands are represented by filled rectangles. $\mathrm{NCHC}$, for example, carried the N-terminal region of NCALD with the remaining portion of HPCA (B) Purified NCALD, HPCA, NCHC and HCNC were spotted onto nitrocellulose and the membrane was then incubated with $\mathrm{S} 100 \mathrm{~B}$ in the presence of indicated concentrations of $\mathrm{CaCl}_{2}$. Binding and analyses were carried out as indicated earlier. Data presented (mean $\pm \mathrm{SEM}$ ) was obtained from at least five independent experiments with three different protein preparations.

\subsection{NCALD and S100B Interact in Living Cells}

The results presented above show that NCALD and S100B bind specifically and the interaction requires the $\mathrm{N}$-terminal region of NCALD. The next step was to investigate if the interaction occurred in living cells. To accomplish this purpose, we used bimolecular fluorescence complementation (BiFC) assay, based on the tagging of two proteins with half of a fluorescent protein (FP) each [37,38]. Upon the interaction of the putative binding partners, the two halves of the fluorescent protein are brought closer, associate with each other and form the functional protein that fluoresces (Figure 3A) [37,38]. In order to investigate the interaction between NCALD and S100B, we fused NCALD and S100B with YFP 1-158 (YN) and YFP 159-238(YC) respectively. Cotransfection with NCALD-YN-pcDNA1 and YC-S100B-pcDNA1 into COS7 cells generated fluorescent signal while transfection of individual constructs alone did not (Figure 3A). The active form of S100B is known to be a dimer. Therefore, we fused S100B with YFP 1-158(YN) and YFP 159-238(YC) and transfected the two constructs into COS7 cells as a positive control. Cotransfection of S100B-YN with YC-S100B into COS7 cells also generated the fluorescent signal. Multiple negative controls including S100B-YN, YC-S100B, NCALD-YN, YN\&S100B-YC, NCALD-YN\&YC and YN\&YC were also tested. The results presented (Figure $3 B$ ) show that specific interaction was observed only between monomeric units of S100B, between S100B and NCALD and between S100B and HPCA. Furthermore, based on positive cells/unit area, the results show statistically significant differences between NCALD-S100B and HPCA-S100B. It remains to be determined if these differences are indicative of different affinities for the interacting pairs, as the in vitro data for NCALD and HPCA suggest (Figures 1 and 2). Nevertheless, the deliberate choice of a non-neuronal, commonly used cell line and the observations underscore the possible ubiquitous nature of these interactions, even in the absence of specialized structures in astrocytes and neurons and specific proteins expressed therein. Another noteworthy difference is the calcium-dependence of the interaction between S100B and its interacting partner: the BiFC experiments demonstrate that interactions were observed after transfection without manipulating the intracellular calcium levels. Based on the rather high calcium concentrations needed to promote interactions in vitro, there are two possible explanations: (1) the interactions within cells are much more stable and robust compared to in vitro and (2) the endogenous calcium levels in COS7 cells are sufficient to promote the interactions. Therefore, it was of interest to investigate the effect, if any, of manipulating intracellular calcium concentrations on these interactions in this scenario. 

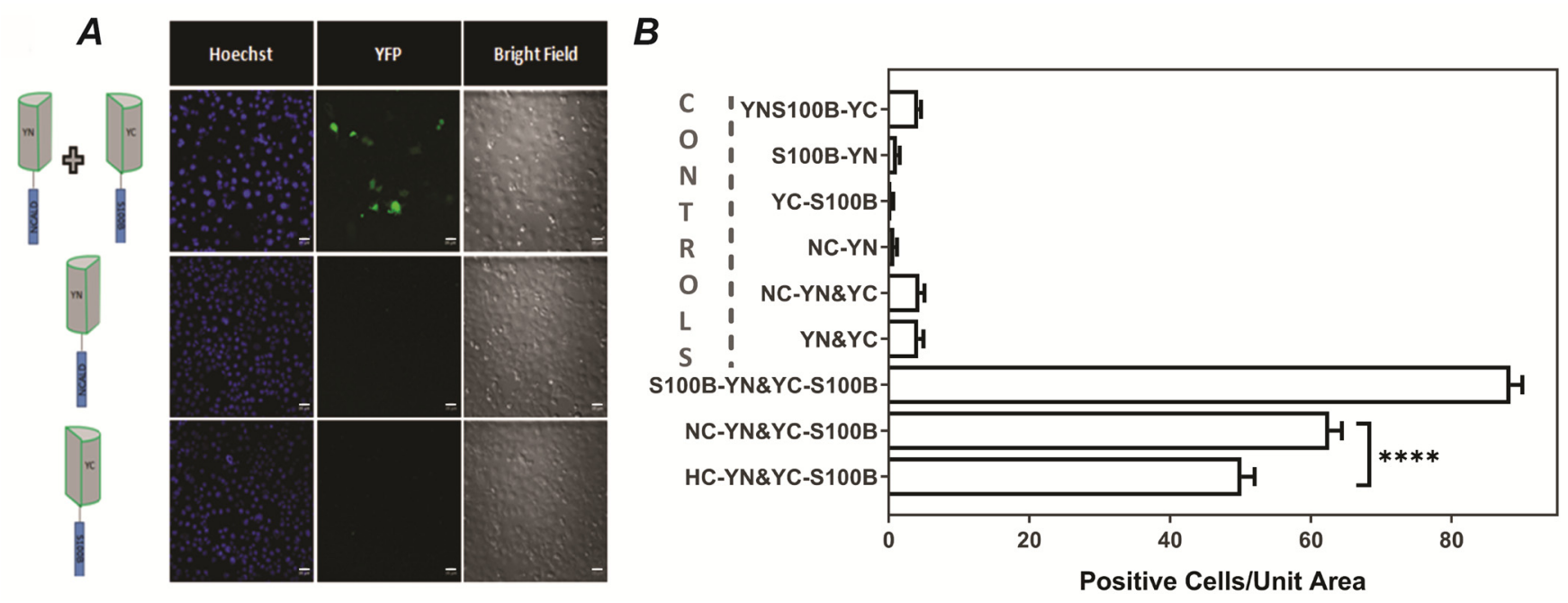

Figure 3. NCALD and S100B interact in living cells: COS 7 cells were cotransfected with constructs NCALD-YN-pcDNA1 and YC-S100B-pcDNA1. Cotransfection of S100B-YN and YC-S100B served as positive control while negative controls include transfection of S100B-YN, YC-S100B, NCALD-YN, YN\&S100B-YC, NCALD-YN\&YC and YN\&YC. Cells were monitored by using Nikon Confocal microscope 48 hours after transfection. (A) Images of transfected cells with vectors individually or together (B) Analysis of complex formation: Positive cells numbers per unit area were obtained. Data from six independent transfections were pooled for controls; for S100B-S100B, NCALD-S100B and HPCA-S100B, data from twenty independent transfections were pooled and plotted in Prism (9.0). ${ }^{* * * *} p \leq 0.0001$. Scale bar $=50 \mu \mathrm{m}$.

\subsection{Translocation of the Complexes in Response to Change in Calcium}

Members of NCS proteins are myristoylated at the N-terminus by N-myristoyl transferase. The myristoyl group allows for the interaction with hydrophobic fragments, which facilitates translocation from the cytosol to membrane fractions [39]. Using live imaging in HeLa cells, translocation of HPCA (fused with fluorescent proteins) into the highly membranous, perinuclear, trans-Golgi network (TGN) region has been demonstrated in response to elevated intracellular calcium $[40,41]$.

We adopted a similar approach to investigate the behavior of the complexes-NCALDS100B, HPCA-S100B and S100B-S100B. We chose the COS7 cell system, which does not express S100B, NCALD or HPCA and is also not a specialized neuronal or astrocytic cell; on the other hand it boasts superior morphology of the endoplasmic reticulum and responds to histamine treatment with altered calcium [42,43]; treatment with histamine, a known physiological modulator, has also been documented to influence translocation of HPCA [41]. More analytical details are presented in Supplementary Materials and the results are summarized in Figure 4. Under normal conditions, fluorescence in transfected cells from all three complexes-NCALD-S100B, HPCA-S100B and S100B-S100B-were found to be diffused throughout the cell. After histamine addition, NCALD-S100B and HPCA-S100B translocated and localized within a specific perinuclear region of the cell rich in trans-Golgi network (TGN) membranes. In contrast, no significant translocation was observable upon histamine addition in cells transfected with S100B-S100B complex. The peak intensity for the translocated NCALD-S100B complex was reached at $3.15 \pm 0.197 \mathrm{~min}(n=20)$ and for the HPCA-S100B complex, at $2.25 \pm 0.443 \mathrm{~min}(n=10)$ after histamine addition. Based on assessment of calcium transients with cotransfected RCaMP, the maximum calcium concentration was reached at $2.11 \pm 0.54 \mathrm{~min}(n=8)$ after histamine addition; this value is comparable to about 1.66 min estimated earlier [43]. Over time, both HPCA-S100B and NCALD-S100B complexes diffused out of the region of interest (Figure 4). However, the kinetics was different: S100B complexed with NCALD stayed at the perinuclear region substantially longer than that complexed with HPCA (Figure 4). The observation suggests that the NCALD-S100B complex may have a broader range of sensitivity to calcium and/or a higher affinity to the TGN when compared to the HPCA-S100B complex. 


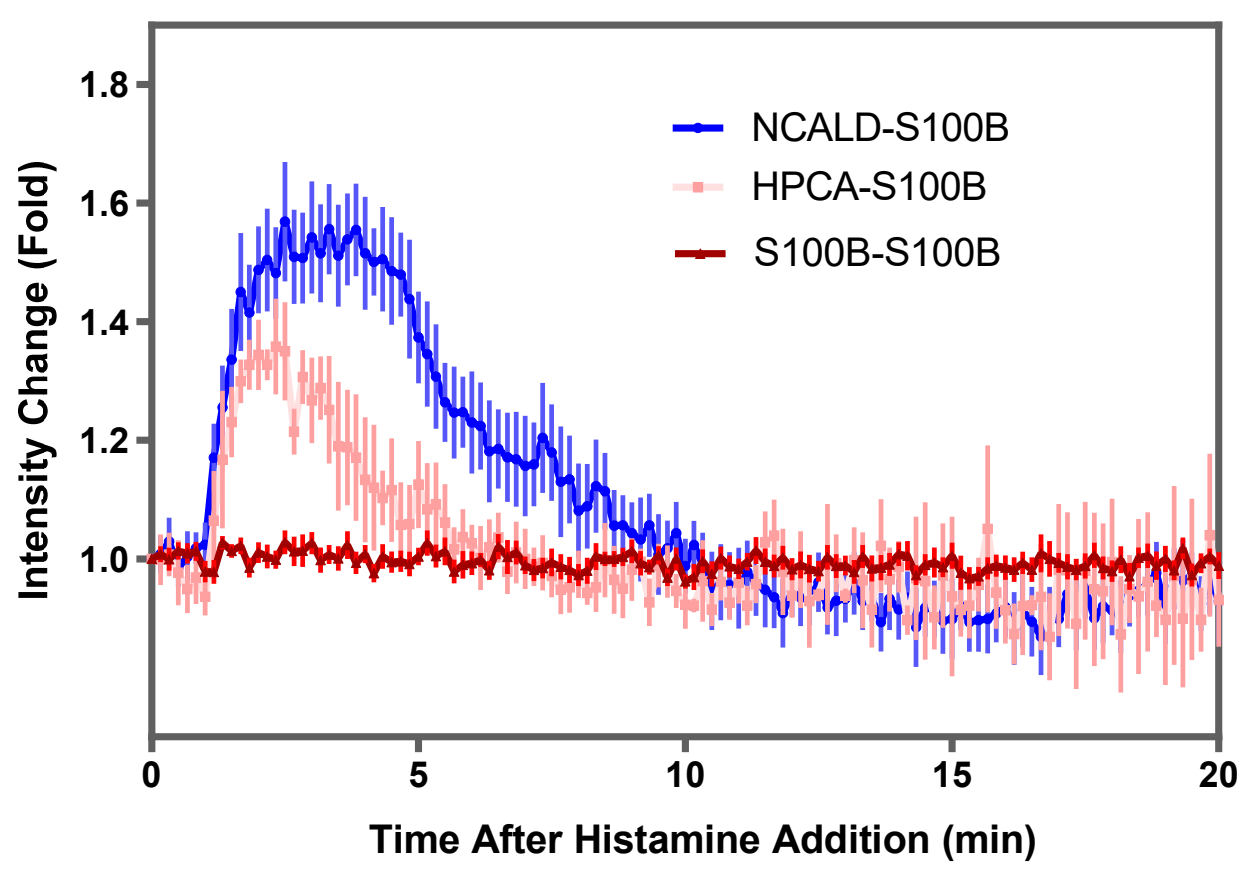

Figure 4. Translocation kinetics of S100B complexes-determination of a change in fluorescent intensities as a function of time: Readings from several experiments were averaged and the mean \pm SEM is presented for the fold-change in fluorescent intensity observed in the trans-Golgi network (TGN) region for cells transfected with YN-NCALD and YC-S100B (NCALD-S100B, blue line, $n=20$ cells); YN-HPCA and YC-S100B (HPCA-S100B, pink lines, $n=10$ cells) and YN-S100B and YC-S100B (S100B-S100B, red line, $n=20$ cells). At least three independent transfections were used to collect the data.

\section{Discussion}

In this report, we demonstrated that $\mathrm{S100B}$ binds NCALD both in vitro and in living cells and identify that the N-terminal region of NCALD that includes the EF1 hand is essential for this binding. Furthermore, the NCALD-S100B complex translocates upon elevation in cellular calcium concentration while the S100B-S100B complex does not. The observations suggest that NCALD serves as a calcium-dependent chaperon for translocating S100B in living cells. It would explain how S100B, mostly found in the cytoplasm, could target proteins in membranous compartments, such as ROSGC1 [31]. While we have focused on the TGN area, it is likely that the complex also translocates to other membranous regions in the cell. As discussed earlier, properties of the S100B protein are not favorable to large hydrophobic interactions after calcium binding; however, those of NCALD are. Thus, a unique and elegant partnering system is created where a normally cytosolic protein, $\mathrm{S} 100 \mathrm{~B}$, binds to another cytosolic protein, NCALD, which enables the complex to be translocated to membrane compartments. A similar role for HPCA might also be envisioned, although the in vitro experiments indicate that its interaction with S100B is weaker compared to NCALD - an observation substantiated by results obtained in cultured cells (Figure 3B). For this reason, we placed more emphasis on the S100B-NCALD interaction.

NCALD, like S100B, is a calcium-sensor protein and is a member of the neuronal calcium sensor (NCS) protein family. It is primarily expressed in the central nervous system, spinal cord, retina, inner ear, olfactory epithelium and zona glomerulosa of the adrenal gland, to name a few [44,45]. It consists of four EF hands although EF1 hand is disabled from binding calcium. A major feature of NCALD is N-terminal myristoylation, which allows NCALD to interact with cell membrane. The myristoyl group is sequestered in the $\mathrm{Ca}^{2+}$ free state in the protein. When it binds to $\mathrm{Ca}^{2+}$, the myristoyl group extrudes, allowing it to interact with the membrane-often described as the calcium-myristoyl switch $[44,46]$. A major consequence of calcium-myristoyl switch is the exposure of the 
buried N-terminus in the calcium-bound state; as a result, the myristoyl chain covalently attached to the N-terminus is also exposed targeting NCALD (and HPCA) to membranous cellular compartments-a feature found in other NCS proteins also [40,41]. Upon elevation of intracellular calcium, NCALD translocates to the perinuclear compartment from cytosol [40]. Another consequence of the calcium-myristoyl switch could also be the exposure of the binding sites located in the N-terminal region to target proteins. Our observations in vitro- that S100B binding to NCALD is calcium-dependent and the binding is mediated by the N-terminal region of NCALD-are consistent with this explanation. It is noted that the conformational changes due to the calcium-myristoyl switch may be assayed in vitro using the calcium induced mobility shift assay (CIMSA) [13]. Further analysis is in progress.

There is direct evidence that the two proteins are expressed in a colocalized fashion in glial cells [35], and different types of neurons, for example, in the Purkinje cells of the cerebellum [47]. Both NCALD and S100B have been independently localized to identical regions in the retina $[31,33,48]$. What could be the physiological significance of this interaction? This report suggests that NCALD (and potentially HPCA) serves as a calcium-dependent chaperone for S100B. As in the retina, NCALD could enable delivery of S100B to common targets-such as ROSGC1, located on the cell membrane-in response to calcium. Interestingly, S100B and NCALD have non-overlapping binding sites on ROSGC1 and, together, may cause a greater stimulation of the catalytic activity with a synergistic effect on downstream pathways. Balanced regulation of ROSGC1 by multiple calcium sensor proteins- and thereby, the production of cyclic GMP and downstream modulation of cyclic-nucleotide gated channels - has been well-documented in phototransductionespecially for the recovery phase in photoreceptor outer segments. In fact, S100B is critical for the recovery phase in cone photoreceptors [49] and regulates polarization activity at the photoreceptor-bipolar synapses [50]. A potential link to melatonin release as the S100B-mediated downstream effect in response to norepinephrine has been demonstrated in the pineal gland [51,52]. Notably, the central role for such opposing or synergistic regulation linked to upstream pathways such as neurotransmitter binding or activation of voltage-gated calcium channels and downstream pathways such as modulation of cyclic nucleotide gated calcium channels and altering calcium homeostasis were proposed [53].

The interaction with NCALD is also likely to mediate trafficking of S100B in response to calcium both in glia and neurons: NCALD is known to bind to cytoskeletal elements and clathrin [54] and regulate endocytosis in spinal muscular atrophy [55,56]. More recently, a role for NCALD has been proposed in neurogenesis in hippocampus [57]. It is noted that the use of BiFC allows interrogation of the NCALD-S100B interaction in a variety of cell types with different calcium transients.

Interacting partners for S100B have included receptors such as RAGE [15], TP53 and its regulatory molecules such as hdm-2 and MDM2 [58,59] and, more recently, amyloidbeta [60]. These interactions impact a variety of signaling processes associated with normal functioning and in diseased states such as cancer and Alzheimer's disease. The calciumdependent physiological consequences of chaperoning of S100B remain to be investigated. It is documented that HPCA can translocate brain type creatin kinase in calcium-dependent fashion [61] and such interactions play a physiological role in hippocampal neurons [62]. Thus, the calcium-dependent interaction between the versatile signaling molecules S100B and NCALD (and HPCA) potentially have significant implications for understanding the distinct roles played by S100B separated in space and time-especially in processes involving dynamic rearrangement of cell membranes, calcium-dependent relocation and secretion of S100B and delivery to targeted interacting partners. Such an understanding may be critical to evaluate S100B as a pharmacological target in the treatment of diseases.

The clinical relevance of the findings is uncharted territory, at this stage, and have to remain speculative. S100B is a versatile signaling molecule that impacts multiple physiological processes ranging from cardiomyocyte remodeling to neuronal regulation, from immune responses to cancer, as discussed earlier. It is possible that a role for this interaction 
may be uncovered in these processes. However, given the large overlap in expression, neurodegenerative diseases may be a good target to begin with.

\section{Materials and Methods}

\subsection{Materials}

Ovalbumin and S100B were purchased from Millipore Sigma (St. Louis, MO, USA).

\subsection{Methods}

\subsubsection{Protein Purification}

pET 21d plasmids encoding NCALD, HPCA, NCHC, HCNC and all the mutants were transformed into ER2566 E. coli cells with coexpressed yeast $\mathrm{N}$-myristoyl transferase. The cells were induced with Isopropyl $\beta$-d-1-thiogalactopyranoside (IPTG). Myristic acid was added to the cells to generate a myristoylated form of the proteins, which were then purified by a single-step procedure as described previously [63]. After concentration, the proteins were washed with calcium-depleted $20 \mathrm{mM}$ Tris $\mathrm{HCl}(\mathrm{pH} 7.5)$ to remove the bound calcium. At least three preparations of two different clones were purified and tested.

\subsubsection{Membrane Overlay Assays}

Two micrograms of NCALD, HPCA or a derivative were spotted onto nitrocellulose and blocked with $3 \%$ BSA in TBS-T for $1 \mathrm{~h}$ at room temperature. The membrane was then incubated with $80 \mathrm{nM}$ of S100B in $50 \mathrm{mM}$ Tris HCl, pH 7.4, 0.1\% Tween-20, $150 \mathrm{mM} \mathrm{NaCl}$, $1 \mathrm{mM} \mathrm{MgSO}_{4}$ and $1 \mathrm{mM} \mathrm{DTT}$, in the presence of indicated concentrations of $\mathrm{CaCl}_{2}(0,0.5$ and $1 \mathrm{mM}$ ). After $1 \mathrm{~h}$ incubation, the blot was washed with the same buffer. Bound S100B was detected using its monoclonal antibody (S2532, Millipore Sigma, Burlington, MA, USA) following standard western blotting protocol and detection by chemiluminescence (Pierce ECL kit, Thermo Fisher Scientific, Waltham, MA, USA). Antibody binding was monitored by using S100B spotted onto the membrane. Intensity values were measured for each spot using Image J and corrected for background.

\subsubsection{Bimolecular Fluorescence Complementation Assays}

Sequences encoding NCALD and S100B were fused to sequences encoding the N(residues 1-158) and C-terminal EYFP (residues 159-238) fragments respectively in pcDNA1 (a kind gift from Dr. Hu). Constructs were transfected into COS7 cells using calcium phosphate buffer. Standard protocols were used $[48,64,65]$. Briefly, the transfection mixture containing HEBS buffer (25 mM HEPES, $140 \mathrm{mM} \mathrm{NaCl}$ and $0.75 \mathrm{mM} \mathrm{Na}_{2} \mathrm{HPO}_{4},(\mathrm{pH} 7.05)$ ), $250 \mathrm{mM} \mathrm{CaCl}_{2}$ and $15 \mu \mathrm{g}$ of plasmid DNA was incubated at room temperature for $30 \mathrm{~min}$ and added to COS7 cells in $35 \mathrm{~mm}$ dishes. After further incubation at room temperature for $30 \mathrm{~min}$, fresh medium was added. Cells were grown for $24 \mathrm{~h}$, and the expression of the fluorescent tagged proteins was analyzed using a C2 confocal laser scanning microscope (Nikon) equipped with Tokai-Hit stage for live imaging. Images were obtained after Hoechst addition $(2 \mu \mathrm{g} / \mathrm{mL})$ for nuclear staining; images were captured before and after histamine addition $(45 \mu \mathrm{M})$. All images were captured on NIS elements using identical parameters. NIH ImageJ software [64] was used to analyze the images. Positive cell numbers were calculated and plotted in Prism.

\subsubsection{Statistics}

Prism (9.0) or SPSS26 was used for analyses. Statistical significance was determined by two-tailed Student's $t$ test. ${ }^{*}, p<0.05 ;{ }^{* *}, p<0.01 ;{ }^{* * *}, p<0.001$. Mean $\pm \mathrm{SEM}$ was used to represent the variations within each group.

\section{Patents}

Portions of the work submitted are currently under disclosure protection (U.S. Provisional Patent Application No. 63/084, 071). 
Supplementary Materials: The following are available online, Details regarding analyses of translocation described in Figure 4, including Figure S1: Estimation by freehand line tool, Figure S2: Estimation by automated area determination.

Author Contributions: Conceptualization, V.V., A.K.; methodology, A.K., J.Z.; formal analysis, J.Z., H.W., V.V.; investigation, J.Z., A.K.; writing-original draft preparation, J.Z., H.W., A.K., V.V.; writing-review and editing, V.V., A.K.; supervision, V.V.; project administration, V.V.; funding acquisition, V.V. All authors have read and agreed to the published version of the manuscript.

Funding: The authors gratefully acknowledge support from the American Osteopathic Association and the Osteopathic Heritage Foundation.

Institutional Review Board Statement: Not applicable.

Informed Consent Statement: Not applicable.

Data Availability Statement: The data presented in this study are available in article and supplementary material.

Conflicts of Interest: The authors declare no conflict of interest.

Sample Availability: Not available.

\section{References}

1. Virchow, R. Über das granulierte Ansehen der Wandlungen der Hirnventrikel. Allg. Z. Psychiatr. 1846, 3, 242.

2. Kettenmann, H.; Verkhratsky, A. Neuroglia: The 150 years after. Trends Neurosci. 2008, 31, 653-659. [CrossRef] [PubMed]

3. Bazargani, N.; Attwell, D. Astrocyte calcium signaling: The third wave. Nat. Neurosci. 2016, 19, 182-189. [CrossRef] [PubMed]

4. Calabrese, E.J.; Dhawan, G.; Kapoor, R.; Iavicoli, I.; Calabrese, V. What is hormesis and its relevance to healthy aging and longevity? Biogerontology 2015, 16, 693-707. [CrossRef] [PubMed]

5. Li, X.; Yang, T.; Sun, Z. Hormesis in Health and Chronic Diseases. Trends Endocrinol. Metab. 2019, 30, 944-958. [CrossRef]

6. Mattson, M.P. Hormesis defined. Ageing Res. Rev. 2008, 7, 1-7. [CrossRef] [PubMed]

7. Donato, R.; Sorci, G.; Riuzzi, F.; Arcuri, C.; Bianchi, R.; Brozzi, F.; Tubaro, C.; Giambanco, I. S100B's double life: Intracellular regulator and extracellular signal. Biochim. Biophys. Acta 2009, 1793, 1008-1022. [CrossRef]

8. Van Eldik, L.J.; Wainwright, M.S. The Janus face of glial-derived S100B: Beneficial and detrimental functions in the brain. Restor. Neurol. Neurosci. 2003, 21, 97-108.

9. Gonzalez, L.L.; Garrie, K.; Turner, M.D. Role of S100 proteins in health and disease. Biochim. Biophys. Acta Mol. Cell Res. 2020, 1867, 118677. [CrossRef]

10. Matsumura, H.; Shiba, T.; Inoue, T.; Harada, S.; Kai, Y. A novel mode of target recognition suggested by the 2.0 A structure of holo S100B from bovine brain. Structure 1998, 6, 233-241. [CrossRef]

11. Wright, N.T.; Inman, K.G.; Levine, J.A.; Cannon, B.R.; Varney, K.M.; Weber, D.J. Refinement of the solution structure and dynamic properties of $\left.\mathrm{Ca}^{(2+}\right)$-bound rat S100B. J. Biomol. NMR 2008, 42, 279-286. [CrossRef]

12. Rezvanpour, A.; Shaw, G.S. Unique S100 target protein interactions. Gen. Physiol. Biophys. 2009, 28, F39-F46.

13. Viviano, J.; Krishnan, A.; Wu, H.; Venkataraman, V. Electrophoretic mobility shift in native gels indicates calcium-dependent structural changes of neuronal calcium sensor proteins. Anal. Biochem. 2016, 494, 93-100. [CrossRef] [PubMed]

14. Ikura, M.; Ames, J.B. Genetic polymorphism and protein conformational plasticity in the calmodulin superfamily: Two ways to promote multifunctionality. Proc. Natl. Acad. Sci. USA 2006, 103, 1159-1164. [CrossRef] [PubMed]

15. Ostendorp, T.; Leclerc, E.; Galichet, A.; Koch, M.; Demling, N.; Weigle, B.; Heizmann, C.W.; Kroneck, P.M.; Fritz, G. Structural and functional insights into RAGE activation by multimeric S100B. EMBO J. 2007, 26, 3868-3878. [CrossRef] [PubMed]

16. Donato, R. Intracellular and extracellular roles of S100 proteins. Microsc. Res. Tech. 2003, 60, 540-551. [CrossRef]

17. Angelopoulou, E.; Paudel, Y.N.; Piperi, C. Emerging role of S100B protein implication in Parkinson's disease pathogenesis. Cell. Mol. Life Sci. 2020. [CrossRef]

18. Astrand, R.; Unden, J. Clinical Use of the Calcium-Binding S100B Protein, a Biomarker for Head Injury. Methods Mol. Biol. 2019, 1929, 679-690. [CrossRef]

19. Dadas, A.; Washington, J.; Diaz-Arrastia, R.; Janigro, D. Biomarkers in traumatic brain injury (TBI): A review. Neuropsychiatr. Dis. Treat. 2018, 14, 2989-3000. [CrossRef]

20. Harpio, R.; Einarsson, R. S100 proteins as cancer biomarkers with focus on S100B in malignant melanoma. Clin. Biochem. 2004, 37, 512-518. [CrossRef]

21. Krishnan, A.; Wu, H.; Venkataraman, V. Astrocytic S100B, Blood-Brain Barrier and Neurodegenerative Diseases. Glia Health Dis. 2020. [CrossRef]

22. Moss, B.P.; Patel, D.C.; Tavee, J.O.; Culver, D.A. Evaluating S100B as a serum biomarker for central neurosarcoidosis. Respir. Med. 2020, 162, 105855. [CrossRef] [PubMed]

23. Wang, K.K.; Yang, Z.; Zhu, T.; Shi, Y.; Rubenstein, R.; Tyndall, J.A.; Manley, G.T. An update on diagnostic and prognostic biomarkers for traumatic brain injury. Expert Rev. Mol. Diagn. 2018, 18, 165-180. [CrossRef] [PubMed] 
24. Arcuri, C.; Fioretti, B.; Bianchi, R.; Mecca, C.; Tubaro, C.; Beccari, T.; Franciolini, F.; Giambanco, I.; Donato, R. Microglia-glioma cross-talk: A two way approach to new strategies against glioma. Front. Biosci. 2017, 22, 268-309. [CrossRef]

25. Chiappalupi, S.; Sorci, G.; Vukasinovic, A.; Salvadori, L.; Sagheddu, R.; Coletti, D.; Renga, G.; Romani, L.; Donato, R.; Riuzzi, F. Targeting RAGE prevents muscle wasting and prolongs survival in cancer cachexia. J. Cachexia Sarcopenia Muscle 2020, 11, 929-946. [CrossRef]

26. Riuzzi, F.; Sorci, G.; Sagheddu, R.; Chiappalupi, S.; Salvadori, L.; Donato, R. RAGE in the pathophysiology of skeletal muscle. J. Cachexia Sarcopenia Muscle 2018, 9, 1213-1234. [CrossRef]

27. Rui, T.; Li, Q.; Song, S.; Gao, Y.; Luo, C. Ferroptosis-relevant mechanisms and biomarkers for therapeutic interventions in traumatic brain injury. Histol. Histopathol. 2020, 18229. [CrossRef]

28. Sagheddu, R.; Chiappalupi, S.; Salvadori, L.; Riuzzi, F.; Donato, R.; Sorci, G. Targeting RAGE as a potential therapeutic approach to Duchenne muscular dystrophy. Hum. Mol. Genet. 2018, 27, 3734-3746. [CrossRef]

29. Tsoporis, J.N.; Mohammadzadeh, F.; Parker, T.G. Intracellular and Extracellular Effects of S100B in the Cardiovascular Response to Disease. Cardiovasc. Psychiatry Neurol. 2010, 2010, 206073. [CrossRef]

30. Pozdnyakov, N.; Goraczniak, R.; Margulis, A.; Duda, T.; Sharma, R.K.; Yoshida, A.; Sitaramayya, A. Structural and functional characterization of retinal calcium-dependent guanylate cyclase activator protein (CD-GCAP): Identity with S100beta protein. Biochemistry 1997, 36, 14159-14166. [CrossRef]

31. Rambotti, M.G.; Giambanco, I.; Spreca, A.; Donato, R. S100B and S100A1 proteins in bovine retina:their calcium-dependent stimulation of a membrane-bound guanylate cyclase activity as investigated by ultracytochemistry. Neuroscience 1999, 92, 1089-1101. [CrossRef]

32. Sitaramayya, A. Calcium-dependent activation of guanylate cyclase by S100b. Adv. Exp. Med. Biol. 2002, 514, 389-398. [CrossRef] [PubMed]

33. Duda, T.; Koch, K.W.; Venkataraman, V.; Lange, C.; Beyermann, M.; Sharma, R.K. Ca( ${ }^{2+}$ ) sensor S100beta-modulated sites of membrane guanylate cyclase in the photoreceptor-bipolar synapse. EMBO J. 2002, 21, 2547-2556. [CrossRef] [PubMed]

34. Wen, J.; Stock, A.D.; Chalmers, S.A.; Putterman, C. The role of B cells and autoantibodies in neuropsychiatric lupus. Autoimmun. Rev. 2016, 15, 890-895. [CrossRef] [PubMed]

35. Okazaki, K.; Obata, N.H.; Inoue, S.; Hidaka, H. S100 beta is a target protein of neurocalcin delta, an abundant isoform in glial cells. Biochem. J. 1995, 306 Pt 2, 551-555. [CrossRef]

36. Viviano, J.; Wu, H.; Venkataraman, V. Evolutionary Interrelationships and Insights into Molecular Mechanisms of Functional Divergence: An Analysis of Neuronal Calcium Sensor Proteins. J. Phylogenetics Evol. Biol. 2013, 1. [CrossRef]

37. Kodama, Y.; Hu, C.D. Bimolecular fluorescence complementation (BiFC): A 5-year update and future perspectives. Biotechniques 2012, 53, 285-298. [CrossRef]

38. Kodama, Y.; Hu, C.D. Bimolecular fluorescence complementation (BiFC) analysis of protein-protein interaction: How to calculate signal-to-noise ratio. Methods Cell Biol. 2013, 113, 107-121. [CrossRef]

39. Burgoyne, R.D. Neuronal calcium sensor proteins: Generating diversity in neuronal $\mathrm{Ca}^{2+}$ signalling. Nat. Rev. Neurosci. 2007, 8, 182-193. [CrossRef]

40. O'Callaghan, D.W.; Ivings, L.; Weiss, J.L.; Ashby, M.C.; Tepikin, A.V.; Burgoyne, R.D. Differential use of myristoyl groups on neuronal calcium sensor proteins as a determinant of spatio-temporal aspects of $\mathrm{Ca}^{2+}$ signal transduction. J. Biol. Chem. 2002, 277, 14227-14237. [CrossRef]

41. O'Callaghan, D.W.; Tepikin, A.V.; Burgoyne, R.D. Dynamics and calcium sensitivity of the Ca ${ }^{2+} / \mathrm{myristoyl}^{2}$ switch protein hippocalcin in living cells. J. Cell Biol. 2003, 163, 715-721. [CrossRef]

42. Avezov, E.; Konno, T.; Zyryanova, A.; Chen, W.; Laine, R.; Crespillo-Casado, A.; Melo, E.P.; Ushioda, R.; Nagata, K.; Kaminski, C.F.; et al. Retarded PDI diffusion and a reductive shift in poise of the calcium depleted endoplasmic reticulum. BMC Biol. 2015, 13, 2. [CrossRef]

43. Lai, P.; Yip, N.C.; Michelangeli, F. Regucalcin (RGN/SMP30) alters agonist- and thapsigargin-induced cytosolic $\left[\mathrm{Ca}^{2+}{ }^{2}\right.$ transients in cells by increasing SERCA Ca $\left({ }^{2+}\right)$ ATPase levels. FEBS Lett. 2011, 585, 2291-2294. [CrossRef]

44. Ladant, D. Calcium and membrane binding properties of bovine neurocalcin delta expressed in Escherichia coli. J. Biol. Chem. 1995, 270, 3179-3185.

45. Vijay-Kumar, S.; Kumar, V.D. Neurocalcin. Role in neuronal signaling. Methods Mol. Biol. 2002, 172, 261-279. [CrossRef]

46. Zozulya, S.; Stryer, L. Calcium-myristoyl protein switch. Proc. Natl. Acad. Sci. USA 1992, 89, 11569-11573. [CrossRef]

47. Uhlén, M.; Fagerberg, L.; Hallström, B.M.; Lindskog, C.; Oksvold, P.; Mardinoglu, A.; Sivertsson, A.; Kampf, C.; Sjöstedt, E.; Asplund, A.; et al. Proteomics. Tissue-based map of the human proteome. Science 2015, 347, 1260419. [CrossRef]

48. Venkataraman, V.; Duda, T.; Ravichandran, S.; Sharma, R.K. Neurocalcin delta modulation of ROS-GC1, a new model of Ca( $\left.{ }^{2+}\right)$ signaling. Biochemistry 2008, 47, 6590-6601. [CrossRef]

49. Wen, X.H.; Duda, T.; Pertzev, A.; Venkataraman, V.; Makino, C.L.; Sharma, R.K. S100B serves as a Ca $\left({ }^{2+}\right)$ sensor for ROS-GC1 guanylate cyclase in cones but not in rods of the murine retina. Cell. Physiol. Biochem. 2012, 29, 417-430. [CrossRef]

50. Venkataraman, V.; Duda, T.; Vardi, N.; Koch, K.W.; Sharma, R.K. Calcium-modulated guanylate cyclase transduction machinery in the photoreceptor-Bipolar synaptic region. Biochemistry 2003, 42, 5640-5648. [CrossRef]

51. Venkataraman, V.; Duda, T.; Sharma, R.K. The alpha(2D/A)-adrenergic receptor-linked membrane guanylate cyclase: A new signal transduction system in the pineal gland. FEBS Lett. 1998, 427, 69-73. [CrossRef] 
52. Venkataraman, V.; Nagele, R.; Duda, T.; Sharma, R.K. Rod outer segment membrane guanylate cyclase type 1-linked stimulatory and inhibitory calcium signaling systems in the pineal gland: Biochemical, molecular, and immunohistochemical evidence. Biochemistry 2000, 39, 6042-6052. [CrossRef]

53. Venkataraman, V.; Nagele, R.G. Calcium-sensitive ROS-GC1 signaling outside of photoreceptors: A common theme. Mol. Cell. Biochem. 2002, 230, 117-124. [CrossRef]

54. Ivings, L.; Pennington, S.R.; Jenkins, R.; Weiss, J.L.; Burgoyne, R.D. Identification of $\mathrm{Ca}^{2+}$-dependent binding partners for the neuronal calcium sensor protein neurocalcin delta: Interaction with actin, clathrin and tubulin. Biochem. J. 2002, 363, 599-608. [CrossRef]

55. Janzen, E.; Mendoza-Ferreira, N.; Hosseinibarkooie, S.; Schneider, S.; Hupperich, K.; Tschanz, T.; Grysko, V.; Riessland, M.; Hammerschmidt, M.; Rigo, F.; et al. CHP1 reduction ameliorates spinal muscular atrophy pathology by restoring calcineurin activity and endocytosis. Brain 2018, 141, 2343-2361. [CrossRef]

56. Riessland, M.; Kaczmarek, A.; Schneider, S.; Swoboda, K.J.; Löhr, H.; Bradler, C.; Grysko, V.; Dimitriadi, M.; Hosseinibarkooie, S.; Torres-Benito, L.; et al. Neurocalcin Delta Suppression Protects against Spinal Muscular Atrophy in Humans and across Species by Restoring Impaired Endocytosis. Am. J. Hum. Genet. 2017, 100, 297-315. [CrossRef]

57. Upadhyay, A.; Hosseinibarkooie, S.; Schneider, S.; Kaczmarek, A.; Torres-Benito, L.; Mendoza-Ferreira, N.; Overhoff, M.; Rombo, R.; Grysko, V.; Kye, M.J.; et al. Neurocalcin Delta Knockout Impairs Adult Neurogenesis Whereas Half Reduction Is Not Pathological. Front. Mol. Neurosci. 2019, 12, 19. [CrossRef]

58. van Dieck, J.; Lum, J.K.; Teufel, D.P.; Fersht, A.R. S100 proteins interact with the N-terminal domain of MDM2. FEBS Lett. 2010, 584, 3269-3274. [CrossRef]

59. Wilder, P.T.; Lin, J.; Bair, C.L.; Charpentier, T.H.; Yang, D.; Liriano, M.; Varney, K.M.; Lee, A.; Oppenheim, A.B.; Adhya, S.; et al. Recognition of the tumor suppressor protein p53 and other protein targets by the calcium-binding protein S100B. Biochim. Biophys. Acta 2006, 1763, 1284-1297. [CrossRef]

60. Cristóvão, J.S.; Morris, V.K.; Cardoso, I.; Leal, S.S.; Martínez, J.; Botelho, H.M.; Göbl, C.; David, R.; Kierdorf, K.; Alemi, M.; et al. The neuronal S100B protein is a calcium-tuned suppressor of amyloid- $\beta$ aggregation. Sci. Adv. 2018, 4, eaaq1702. [CrossRef]

61. Kobayashi, M.; Hamanoue, M.; Masaki, T.; Furuta, Y.; Takamatsu, K. Hippocalcin mediates calcium-dependent translocation of brain-type creatine kinase (BB-CK) in hippocampal neurons. Biochem. Biophys. Res. Commun. 2012, 429, 142-147. [CrossRef] [PubMed]

62. Markova, O.; Fitzgerald, D.; Stepanyuk, A.; Dovgan, A.; Cherkas, V.; Tepikin, A.; Burgoyne, R.D.; Belan, P. Hippocalcin signaling via site-specific translocation in hippocampal neurons. Neurosci. Lett. 2008, 442, 152-157. [CrossRef] [PubMed]

63. Krishnan, A.; Viviano, J.; Morozov, Y.; Venkataraman, V. Single-column purification of the tag-free, recombinant form of the neuronal calcium sensor protein, hippocalcin expressed in Escherichia coli. Protein Expr. Purif. 2016, 123, 35-41. [CrossRef] [PubMed]

64. Krishnan, A.; Duda, T.; Pertzev, A.; Kobayashi, M.; Takamatsu, K.; Sharma, R.K. Hippocalcin, new Ca $\left({ }^{2+}\right)$ sensor of a ROS-GC subfamily member, ONE-GC, membrane guanylate cyclase transduction system. Mol. Cell. Biochem. 2009, 325, 1-14. [CrossRef] [PubMed]

65. Krishnan, A.; Venkataraman, V.; Fik-Rymarkiewicz, E.; Duda, T.; Sharma, R.K. Structural, biochemical, and functional characterization of the calcium sensor neurocalcin delta in the inner retinal neurons and its linkage with the rod outer segment membrane guanylate cyclase transduction system. Biochemistry 2004, 43, 2708-2723. [CrossRef] [PubMed] 